\title{
NRCMS and Rural Household Credit Availability in China: Evidence From CFPS
}

Jin Liu ( $\square$ liu.jin@mail.shufe.edu.cn )

Shanghai University of Finance and Economics

Qing Xu

Shanghai University of Finance and Economics

\section{Qing Yang}

Shanghai University of Finance and Economics

Yufeng Lu

Shanghai University of Finance and Economics

\section{Research}

Keywords: Public Health Insurance, Credit Availability, Inclusive Finance, New Rural Cooperative Medical Scheme (NRCMS), rural financial environment, China

Posted Date: July 6th, 2020

DOI: https://doi.org/10.21203/rs.3.rs-39364/v1

License: (c) (i) This work is licensed under a Creative Commons Attribution 4.0 International License. Read Full License 
NRCMS and Rural Household Credit Availability in China: Evidence from CFPS Jin Liu ${ }^{1,2, *}$, Qing Xu1, 2 , Qing Yang 3 , Yufeng $\mathrm{Lu}^{2}$

${ }^{1}$ Research Institute for Agriculture, Farmer and Rural Society in China, Shanghai University of Finance and Economics

2 Institute of Finance and Economics, Shanghai University of Finance and Economics

${ }^{3}$ School of Public Economics and Administration, Shanghai University of Finance and Economics

*Corresponding author: Jin Liu, liu.jin@mail.shufe.edu.cn(J.L.);

\begin{abstract}
:
Background: The Chinese government has, in seeking to enable farmers to obtain and use safe and affordable formal financial services, implemented Inclusive Finance. But disease burden, poor health and other factors have made it difficult for farmers to obtain formal credit services
\end{abstract}

Methods: This paper draws on 2010 China family survey (CFPS) data to explore how the New Rural Cooperative Medical Scheme (NRCMS) affected rural households' credit availability.

Results: The results show that, as a public health insurance system sustained by the participation of government investment participation, the NRCMS provides good 'collateral' and significantly enhances farmers' credit availability level.

Conclusions: Our study suggests the positive impacts is mainly reflected in the economic effect of the NRCMS. This raises the question of how to make better use of the NRCMS' mortgage function, promote inclusive finance and provide more financial services for farmers that will promote their income. This serves to confirm and underline the importance of relevant policies.

Keywords: Public Health Insurance; Credit Availability; Inclusive Finance; New Rural Cooperative Medical Scheme (NRCMS); rural financial environment; China 


\section{Introduction}

Farmers, who are the main part of the rural economy, normally face capital constraints when making production investment decisions and a good rural credit environment can change farmers' initial endowment, which can make an important contribution to expanding production scale and increasing agricultural investment and income (Feder et al., 1990). Agricultural production is vulnerable to climate change and pests. It is naturally risky and farmers' income lacks stability, especially in poor harvest years when they need to use loans to smooth consumption (Duong \& Izumida, 2002). At the end of 2004, the United Nations proposed the concept of Inclusive Finance, which sought to expand the availability and use of financial services. In 2013, Inclusive Finance was first brought up in the Third Plenary Session of the $18^{\text {th }} \mathrm{CPC}$ Central Committee. The Government issued several policy documents, including Opinions on the Development of Financial Services for Agriculture, Countryside and Farmers and Notice on Promoting the Development Plan of Inclusive Finance (20162020). These established strong policy support for inclusive financial development and help to alleviate the lack of formal credit for rural financial services, ${ }^{(1)}$ which especially benefit low-income farmers.

The current rural financial environment and more general regulatory arrangements in China causes a lack of effective collateral for farmers and insufficient credit supply from formal financial institutions. Most serious bank and insurance exclusion therefore occur in rural areas (Stigliz and Weiss, 1981), and poorer households have lower probability to enter the informal credit market (Yuan and $\mathrm{Xu}, 2015$ ). The lack of

(1) The China Household Financial survey report (2014) was released by the China Family Financial investigation and Research Center in 2015. It showed the availability level of formal credit in rural areas was only 27.6 percent in 2014. 
available financial services will prevent rural residents from removing financial constraints, and this will make it difficult to reduce their production capital constraints, which is not conducive to poverty relief or income growth. Health shocks, and major diseases in particular, can not only just impact farmers' savings in the short-term, but their impacts appear to be longer lasting and, perhaps, more malleable (Smith, 2015). The future expected income of families will be severely affected, and this will reduce their ability to repay and will significantly increase the default rate of credit. It is difficult for formal finance to provide credit for sick farmers. In fact, Li et al. (2016) had showed that around $54.9 \%$ of the 918 respondents in South China were credit constrained formal finance. More importantly, as the original rural medical security system gradually collapses, rural residents' income slowly grows, medical expenses increase, financial system arrangements for providing medical credit services weaken and illness forces more rural residents back into poverty.

The survey data of the Poverty Alleviation Office of the State council shows that 42 percent of 7 million poor peasants were poor because of illness at the end of 2015 in China. ${ }^{2}$ Poverty due to illness is one of the root causes of rural poverty in China, and $51.63 \%$ attributing their poverty to the illness of household members in rural China(Zhou et al., 2020). The Government, therefore, implemented the pilot work of the New Rural Cooperative Medical Scheme (hereafter referred to as NRCMS) in 2003 by registering capital in medical insurance.

A large number of studies have shown that NRCMS positively impacts the health of participating farmers and are effective in increasing access to care (Cheng et al., 2015; Hou et al., 2014; Wagstaff et al.,2009; Zhong, 2011) and emphasize the role of nutrition or consumption (Bai and Wu, 2014), labor supply or mobility (Qin et al., 2014; Shen et al., 2017; Zhang et al., 2016). Recently, Lai et al.(2018) have played their eyes on the distribution of benefits under the NCMS across economic groups.

However, these contributions do not sufficiently acknowledge the impact of

(2) Sohu News Network: Multidimensional Elimination of 'poverty due to illness', January 14,2016(http://mt.sohu.com/20160114/n434484593.shtml) 
NRCMS on capital factor. Research into the implementation effect of the NRCMS should also take its impact on farmers' level of credit availability into account. Narrow subject perspectives have meant that the impact of NRCMS on farmers' formal credit availability has not previously been considered within the framework of Inclusive Finance. This study will rectify this shortcoming.

Theoretically, 'promising government' can, in being addressed to the serious shortage of basic financial services for rural households in poverty-stricken areas, create a suitable environment for financial development and promote financial institutions that provide financial services to the poor through grassroots work, infrastructure measures and policy support. From this perspective, the NRCMS embodies the specific Government intervention and applies both explicit and implicit functions. In the first, there is a partial system, which means participating farmers can pay medical expenses in advance and then be reimbursed in accordance with the local compensation policy at the end of the medical treatment, which reduces farmers' economic expenditure to a certain level. But it can disperse the risk of serious illness, and (respectively) improve the availability and level of health care and medical care, and this potentially increases future income and the ability to pay debts.

In the second (implicit) function, the Government implements the system by directly injecting medical insurance, which is Government intervention. When farmers have medical expenses, they will receive a certain proportion of reimbursement compensation, and this can provide good 'collateral' for farmers' credit. This means the Government can provide a 'government credit' mortgage to farmers that reduces their credit constraints when they need to borrow money for medical treatment.

In being framed against the background of the deepening reform of China's rural financial system, the NRCMS appears as an important supplement to rural finance. Its role is especially important in relation to inclusive financial policy, where it functions as a rural financial supplementary system and improves farmers' health benefits and their level of medical security.

This raises the question of the actual impact of the NRCMS on farmers' access to 
formal credit. Current studies rarely take this into account, and this paper seeks to resolve this shortcoming. This paper uses the 2010 China Family Panels Survey (CFPS) data to address this question and, in so doing, does not only seek to evaluate the effect of the NRCMS from a new perspective but also seeks to address weaknesses in research that considers how credit is made available to farmers through the NRCMS. It draws on practical experience to promote Inclusive Finance, the deepened reform of the rural financial system, increased farmer income and rural development.

The second part of this paper will mainly discuss the impact mechanism of the NRCMS and its implications for farmers' formal credit availability; the third part will set out data, variable selection and the setting of the empirical model; the fourth part will discuss empirical results, and the final part will set out the main conclusions and policy implications.

\section{The Influencing Mechanism of NRCMS and Farmers' Formal Credit}

\section{Availability}

Research into the factors that influence farmers' formal credit availability primarily focuses on information asymmetry in the rural credit market, including the information screening of farmers before lending, the incentives for farmers to perform contracts after lending and the enforcement of penalties when farmers breach contracts.

Collateral can solve these adverse selection and moral hazard problems in the credit market (Stigliz and Weiss, 1981), and some scholars have mainly focused on how it can improve farmers' formal credit availability (Feder et al., 1988). But Chinese farmers generally lack effective collateral, which weakens the role that it can play in the rural formal credit market. Rural China is more of a typical 'acquaintance society' (Fei, 1985) and empirical studies show that social capital, such as the 'relationship network', has significantly increased farmers' access to formal credit. For example, 
Yuan and $\mathrm{Xu}(2015)$ had pointed that the poor were limited by social network and that they had no financial means to invest in their social capital to expand their social network.

But few researchers have considered the impact of the NRCMS on farmers' credit availability. As has already been noted, the NRCMS does not just reconstruct China's rural medical security system but also, to some extent, 'redeems' the lack of this system. It theoretically performs the role of a financial supplement system while improving the level of farmers' medical security through both explicit and implicit functions. In the first instance, by increasing participating farmers' use of medical services, it contributes to improved health conditions, provides a healthy basis for maintaining or improving their labor capacity and also helps to improve debt repayment ability - in each of these respects, it produces clear health effects.

In the second instance, with regard to compensation and reimbursement policy, it does not just alleviate the medical burden of participating farmers, but also provides 'collateral' for farmers' credit (mainly the sick people) and reduces the credit constraint to some extent, which in turn improves the possibility of formal credit availability. In this second instance, it produces economic effects.

\section{(I) Health effects}

Health, when defined as an important 'viable ability' (Sen, 1999), appears as the basis of all human activity. Many previous studies confirm the impact of health on farmers' economic behavior and also highlight other potential benefits. Previous studies have showed that health significantly impacts labor efficiency and labor participation (Cai, 2010; Cai et al., 2014; Grossman, 1972; Mushki, 1962; Strauss,1986), and even household asset holdings (Mitra et al., 2016). In a word, the health status undoubtedly affects the solvency of farmers' families. In the current rural formal credit market, peasant households generally lack collateral and the only exception is the small number of wealthy peasant households who can obtain large amounts of credit through this 
means. The microfinance ${ }^{(3)}$ promoted by rural credit institutions therefore focuses to a greater extent on farmers' credit qualifications. In addition to the current income and property of peasant households, which act as hard credit conditions, rural credit cooperatives and agricultural and postal saving banks generally take the health status of peasant households into account. In fact, health shows the future solvency of farmers to some extent, which means it plays a signaling role in the credit process. Theoretically, the NRCMS can improve farmers' credit availability level through health effects.

\section{(II) Economic effects}

Peasant households' credit default is mainly caused by passive default, and especially by accidental passive default as a result of being overburdened (including serious illness and other shocks). Medical risk therefore provides an important incentive for farmers to default on credit. The imperfection of rural financial markets, insufficient supply willingness of rural formal credit institutions and even exclusion of supply have produced a 'reluctant to lend, prudent to lend' mentality, which has produced low availability of formal credit for farmers and prominent illness-related poverty. The Chinese government directly invested in medical insurance by establishing the NRCMS with the aim of addressing this form of poverty in peasant households and reducing the economic and medical burden on farmers. In recent years, it has continuously increased financial investment, improved the level of compensation, expanded the scope of compensation for diseases and medicines and promoted the implementation of the major illness insurance system.

The credit supply suggests that it is precisely because farmers are facing medical credit constraints that the government intervenes in the rural medical insurance market and draws on the NRCMS to compensate for the insufficient supply of rural financial

\footnotetext{
(3) Microfinance is based on farmers' credit qualifications, which require no collateral. The amount is small and does not generally exceed 50,000 yuan. The sample amount of formal credit in this paper does not exceed 50,000 yuan accounts for 93.2 percent of all formal credit samples. Further, the sample proportion of 0-10,000 (including), 10,000-20,000, 20,000-30,000 and 40,000-50,000 yuan is (respectively) 44.8, 24.5,16.6, 3.7 and 3.6 percent. Most farmers currently mainly borrow through microcredit.
} 
system. In addition to improving farmers' medical security level, the NRCMS also plays a financial supplementary role and therefore helps farmers, and the poor in particular, to benefit from financial services.

In the first instance, implementation of the NRCMS enables farmers to obtain compensation for medical expenses in accordance with the principle of compensation and reimbursement by grades and segments. This reduces their medical expenses and medical economic burden, which lowers their risk of credit default and improves their access to credit. In the second instance, moral hazard and supplier-induced demand in the medical service market means that the medical economic burden of participating farmers may increase, which raises the risk of credit default and decreases the level of credit that is available to farmers. But the NRCMS, which is an important part of the social security system, can be regarded as a kind of 'credit collateral' that is endorsed by the Chinese government, which helps to improve farmers' credit availability and reduce credit constraints. The NRCMS may therefore stimulate farmers to obtain credit by reducing or aggravating the medical economic burden, which would show positive or reverse economic effects.

In conclusion, the NRCMS' health and economic effects will affect farmers' credit qualification, and this will then theoretically have a certain impact on their formal credit availability.

\section{Data Description, Variable Selection and Empirical Model Setting}

\section{(I) Data description}

This paper uses information taken from the baseline data of the 2010 China Family Panel Studies (CFPS) that was released by Peking University. This data reflects changes in China's economy, education, health, population and society by tracking and collecting information from individuals, families and communities. In 2010, the CFPS baseline survey covered 25 provinces/municipalities/autonomous regions with a 
sample size of 14798 households, including all family members.

Most rural families participate in the NRCMS, although a small number of family members also use other medical insurance, such as urban workers' medical insurance and supplementary medical insurance. In order to better test the impact of the NRCMS on farmers' formal credit availability, this paper excludes urban samples that lack key variables, along with samples that include participation in other medical insurance. The final effective samples contain 6020 households.

\section{(II) Definition of variables}

1. Variable of Households' Credit Availability

This paper measures households' credit availability by referring to 'whether or not' and 'how much', which institutes two indicators of credit availability and credit quota: (1) the value is ' 1 ' if the household get a loan, and in all other instances it is ' 0 '; (2) credit quota is the amount of loans that households receive. The formal credit mentioned in this paper includes bank and credit cooperative loans, which will not be repeated later.

\section{Variables of the NRCMS}

In applying the CFPS questionnaire, this paper uses two variables to measure participation in the NRCMS.

(1) 'Whether they participate in the NRCMS'. The value is ' 1 ' if the answer is yes, and is ' 0 ' in all other instances. This is because formal credit is mainly applied in the name of hosts of households, which means that the household host is the decision-maker who is legally directly responsible for the 
household's credit behavior. Second, the householder's participation or nonparticipation conveys the information of the family's risk type and repayment ability to some extent.

(2) The proportion of family members who participate in the NRCMS (i.e. the rate of family participation). Theoretically, when more family members participate, there will be a greater cushioning effect on the impact of family health risk. This can then reduce the credit risk created by health shock and improve the level of formal credit availability.

\section{Intermediate variables}

The previous theoretical mechanism established that the NRCMS may affect farmer's availability through health and economic effects. The paper's intermediary variable of health effect is the self-assessment status variable, which presumes that credit applicants are generally household hosts. The intermediary variable of economic effect is if the family faces medical economic pressure. The CFPS questionnaire divides health condition into 'healthy, general, relatively unhealthy, unhealthy and very unhealthy'. This paper defines 'healthy' and 'general' as 'healthy', with a value of '1'; and defines the rest as 'unhealthy', with a value of ' 0 '. In addressing the variable of 'whether the family is facing medical pressure', this paper uses the methods to express whether the family medical cost/annual income exceeds 20, 40 and 60 percent. If it exceeds, it will face the medical economic pressure and have a value of 1 ; in all other instances, its value is 0 .

\section{Other control variables}

Like other studies, this paper also controls the characteristic variables of householders in order to better understand the impact that householder characteristics 
have on farmers' formal credit availability. These characteristics include age, education level (years), gender and marital and political status. In CFPS questionnaires, political status means 'whether the individual participates in the Party' and it is a ' $0-1$ ' variable. If the answer is 'yes', the assigned value would be ' 1 ', but in all other instances the value would be ' 0 '. It should be clarified that although the CFPS questionnaire about (Party) organizations does not just contain the Communist Party of China Party(CPC), but also eight democratic parties ${ }^{(}$, the administrative-area people’s congresses of the People's Republic of China, the administrative-area committee of the Chinese People's Political Consultative Conference and other organizations. However, the farmers hardly participate in these parties or organizations except for the CPC. This paper therefore divides this part into a sample of the CPC members.

Marital status is a ' $0-1$ ' variable and married or cohabitation is a married state that is assigned a value of ' 1 '. Unmarried, divorced or widowed are non-marital states are assigned a value of ' 0 '. Family characteristic variables include family net income(yuan), financial assets, gift expenditure ${ }^{5}$, land assets and real estate, and all of these variables are logarithmic in the process of empirical analysis. In taking into account that the endowment insurance may reduce liquidity constraints, and then have a certain impact on credit access, the family characteristic variables also count the rate of endowment insurance. This paper also controls the characteristics of villages and provinces.

\section{(III) Empirical Model}

First, in taking into account the fact that the credit availability of rural households is a typical binary variable (which means the value is either " 0 " or " 1 "), this paper adopts the Probit model to estimate the impact of the NRCMS on the credit availability of rural households. The Model is set as follows:

\footnotetext{
(4) The Revolutionary Committee of the Chinese Kuomintang, China Democratic League, China National Democratic Construction Association, China Association for Promoting Democracy, Chinese Peasants and Workers Democratic Party, China Zhigong Party, Jiusan Society, Taiwan Democratic Self-Government League.

(5) In the CFPS questionnaire, financial assets include bonds, cash, funds, real estate, savings, stocks and the value of existing housing. Land assets are calculated on the basis of McKinney's (1993) method, which assumes that 25 percent of household agricultural income comes from land and 8 percent from land income.
} 


$$
P(y=1 \mid x)=\Phi\left(\alpha_{0}+\alpha_{1} x_{1}+\sum_{i=2}^{n} \alpha_{i} x_{i}+\mu_{i}\right)
$$

In formula (1), $\mathrm{y}$ is the variable of credit availability; $\mathrm{P}(\mathrm{y}=1)$ represents the possibility of getting a loan; $\Phi(\cdot)$ is the cumulative distribution function of normal distribution; $\mathrm{x} 1$ is the variable of NRCMS; $x_{2} 、 x_{3} \ldots x_{n}$ are control variables, which include household characteristics such as age, education level, gender, marital and political status and the square of age/100 (this takes into account the non-linear impact of age); it also includes family characteristics like financial assets, gift payments, land assets, net income and real estate. Meanwhile, $\mathrm{u}$ is the random interference term.

Second, because the paper engages many household samples that have zero credit, the estimations will be inconsistent if we apply OLS regression to them (Wooldridge, 2003). The Tobit Model can correct the deviation caused by limit variables, and this will enable us to incorporate the sample with zero credit amount into the model. This paper therefore uses the Tobit Model to estimate the impact of the NRCMS on farmers' credit. The models follow:

$$
\ln (1+\text { loan })=\beta_{0}+\beta_{1} x_{1}+\sum_{j=2}^{n} \beta_{j} x_{j}+\mu_{j}
$$

In the formula, loan represents the credit amount; $x_{1}$ is the NRCMS variable; $x_{2}$ 、 $X_{3} \ldots X_{n}$ are control variables; and $u$ is the random interference term. In addition, the credit amount loan in the form of logarithmic is used to make its distribution closer to the normal distribution as this helps to meet the regression model's hypothetical model. $\ln (1+$ loan $)$ is also used in logarithmic form to ensure that variables are still meaningful at the value of 0 .

Third, in order to ensure the mediating role of health and economic effect in the NRCMS, this paper adopts the following mediating effect model:

$$
\begin{aligned}
& y=\beta_{1} x_{1}+\beta_{2} x_{2}+\ldots+\beta_{n} x_{n}+\mu_{1} \\
& m=\beta_{1} x_{1}+\beta_{2} x_{2}+\ldots+\beta_{n} x_{n}+\mu_{2}
\end{aligned}
$$




$$
y=\beta_{1} x_{1}+\beta_{2} x_{2}+\ldots+\beta_{n} x_{n}+\delta \cdot m+\mu_{3}
$$

Of them, $y$ is the variable of households' formal credit availability and $m$ is the intermediate variable.

With regard to the significance test of intermediary effect, this paper draws on the research of Baron and Kenny (1986) to apply the following criteria to estimate: first, the intermediary variable is regressed to the variable of NRCMS as Model (4), and the variable NRCMS is found to be significant; Second, the dependent variable, called as farmers' formal credit availability, is regressed to the independent variable of NRCMS as Model (3), and here the variable of NRCMS is also found to be significant; third, the dependent variable 'farmers' formal credit availability" is regressed to the intermediate variable and the variable of NRCMS at the same time as Model (5). If the intermediate variable is significant, and the coefficient of the NRCMS gets smaller and is found to be significant, then the intermediary variable has a partial mediating effect. If the coefficients of the variables of the NRCMS decrease and show no significance, the intermediate variable has complete mediating effect.

\section{Analysis of Empirical Results}

\section{(I) Analysis of the samples' basic descriptive statistical results}

Table 1 shows the basic descriptive statistical characteristics of the main variables. From the view of farmers' credit availability, the availability of formal credit is 0.114 , which means 11.4 percent of farmers get formal credit, and the average amount of formal credit is only 2,969.0 yuan per household. When assessed from the perspective of the availability of informal credit, 31.0 percent of farmers can obtain informal credit and the credit line is about 5,600 yuan ${ }^{(}$per household, which is almost twice the amount of formal credit. This shows that informal credit is still the main form of credit

(6) The availability of informal credit and credit amount data are not variables, and they are not therefore listed in Table 1. 
in rural areas, and this means it is still hard to make formal credit available to farmers. With regard to NRCMS variables, the average value of 'whether to participate in NRCMS' is 0.869 , which means that 86.9 percent of rural households participate. Meanwhile, the proportion of family participation in the NRCMS is 0.820 , which confirms that 82.0 percent of the family members from rural families participate in the NRCMS.

The average householder is around 50 years-of-age and is basically educated to primary school level (4.7 years); 7.6 percent are party members, 89.5 percent are married, 80.6 percent are male; and 78.7 percent enjoy good health. The average amount of a family has four members and each household has an average net income of about 23,000 yuan, and this indicates that the rural income level is still comparatively low. Household financial assets are about 5,500 yuan, and include bonds, cash, savings and stocks. When calculated on the basis of a four-person household, average money would be less than 1,400 yuan, including both cash and savings. Households' real estate and land assets (respectively) have nearly 90,000 and 30,000 yuan. It appears that the level of rural estate and land assets is not low but that rural real estate and land assets are far less liquid than urban assets because rural land ownership is collective, which means it is more secure in these areas. Family gift expenditure is about 1,600 yuan, which is a quarter of the family financial assets, and this indicates that the cost of maintaining social relations in these areas also increases. The participation rate of family endowment insurance is only 7 percent because pilot implementation of the new rural endowment insurance only began in 2009. The previous rural endowment insurance system is not perfect in many respects, and this is reflected in a low participation rate of rural endowment insurance. Medical pressure ${ }^{\circledR}$ is also a factor, as almost one-third (30 percent) have a medical economic burden. Table 1 lists the relevant variables of village characteristics.

(7) This article only lists the medical pressure if the family medical expense/annual income exceeds 20 percent. 


\section{(II) The Impact of NRCMS on farmers' formal credit availability}

Table 2 reports regression results for the impact of NRCMS on farmers' formal credit availability. The Probit model is used in the first and second columns. The explanatory variables are the availability of formal credit for farmers, and the core explanatory variables of NRCMS are 'whether to participate in the NRCMS' and the participation rate. Other variables are controlled. Column (3) and (4) use the Tobit Model, the explained variable is the farmers' formal credit amount, and the core explanatory and control variables are the same as in columns (1) and (2).

Column (1) and (2) show that the NRCMS variables are (respectively) significant at 5 and 1 percent levels, and this confirms that the NRCMS improves the availability of farmers' formal credit. Column (1) specifically shows that participating households are more likely to obtain formal credit than households without participation. With regard to marginal effect, the possibility of formal credit for participating households is 3 percent

${ }^{8}$ higher than for non-participating households. The household's application for formal credit is normally decided by the host, and the decision reflects the ability to resist health risk, and also indicates information about the family's risk type and repayment ability to some extent. The possibility that householders will participate in formal credit will accordingly increase as a result. Column (2) shows that the proportion of household participation will significantly positively affect increases in the formal credit that is made available to farmers. A marginal effect perspective suggests that the probability that farmers will obtain formal credit increases by 1.8 percent for each increase in the unit of household participation. The Tobit regression results for columns

(8) The formulas are as follows: $\frac{\partial P(y=1 \mid \mathbf{x})}{\partial x_{k}}=\frac{\partial P(y=1 \mid \mathbf{x})}{\partial\left(\mathbf{x}^{\prime} \boldsymbol{\beta}\right)} \cdot \frac{\partial\left(\mathbf{x}^{\prime} \boldsymbol{\beta}\right)}{\partial x_{k}}=\Psi\left(\mathbf{x}^{\prime} \boldsymbol{\beta}\right) \cdot \boldsymbol{\beta}_{k}$. Besides, the marginal effect here refers to the average marginal effect, i.e. the simple arithmetic average is performed after calculating the marginal effect on each sample observation value separately. 
(3) and (4) show that the two NRCMS variables have a significant positive impact on farmers' formal credit, and this impact is also shown in Probit regression.

In turning to the control variable characteristics and focusing on age, we observe that the coefficients of the square of host's age/100 are all negative and significant at a 1 percent level, which means that the relationship between age and credit availability is inverted in a ' $u$ ' shape. The explanation mechanism establishes that young householders have insufficient ability to pay debts because of limited income, and this lowers their formal credit availability. But as they get older, the income gets higher, and their repayment ability also increases. Meanwhile, a fall in the repayment ability of the elderly causes lower credit availability due to the gradual deterioration of various abilities such as labor efficiency.

With regard to education level, the household's length of education is not statistically significant, and this may be related to the fact that most farmers are educated to primary school level or below. The question of whether the host is a Party member

has a significant positive effect, mainly because most rural Party members are village branch cadres or veterans - this gives them a certain capital in social relations, and makes it easier for them to obtain formal credit than other non-Party hosts. Although farmers who are male or married are more likely to get formal credit, this is not statistically significant.

With regard to family characteristics, the coefficient of family population is positive, and this indicates that when the family is larger it is more likely that formal credit will be obtained, although again this is not significant. The logarithmic coefficient of net household income is however significantly positive, and this indicates that when income is higher, solvency will be stronger and it is more likely that formal credit will be obtained. The logarithm of financial assets is significantly negative in the model, which shows that farmers' financial assets cannot improve the availability of their formal credit. This is because the decision-maker of credit demand usually gives priority to internal financing before considering external financing. When farmers have 
more financial assets, it is less likely they will face credit constraints. The demand for external financing through formal credit institutions will be smaller, and they will get fewer loans. The logarithm of household property is not significant, which indicates that household property does not significantly impact farmers' access to formal credit, and this may be related to the fact that rural property cannot be effectively mortgaged.

The logarithm of land assets is significantly positive at the level of one percent, which indicates that farmers' land value positively impacts their access to loans. Gift expenditure logarithm is significantly positive, and this indicates that rural social capital positively affects farmers' access to formal credit. The negative participation rate of family endowment insurance indicates there is a lower possibility of obtaining credit, but it does not pass the significance test, and this may be related to the low level of rural endowment insurance. Village characteristics also have a significant positive impact on farmers' credit availability.

Table 2 Impacts of NRCMS on Householders' Formal Credit Availability

\section{(III) Test of Health Effect of NRCMS}

The previous results comprehensively prove that the NRCMS has a significant positive impact on farmers' access to formal credit. But this raises the question of which kind of route that the NRCMS operates through to affect farmers' access to formal credit. This section initially asks if the NRCMS has significantly improved the health status of farmers and if the health of farmers with intermediary variables has significantly affected the formal credit availability level. Table 3 shows the regression results obtained for the impact of the NRCMS (on formal credit availability through health).

First, the regression results in column (1) of Table 3 show that the coefficient of participation of the head of household is positive, and this indicates that the NRCMS 
has a certain health effect. Also consider marginal effect. When conditions are unchanged, the probability of household hosts that participate in the NRCMS is about 1 percentage higher than households that do not participate in it. The obtained result is not statistically significant.

Now consider the impact of householders' health on credit availability. The regression results in columns (2) and (3) of Table 3 show that the influencing coefficient of householders' health on credit availability and credit amount is significantly negative at a one percent level, which indicates that householders' health level of householders has a significant negative effect on their credit availability. The test criteria of the intermediary effect shows that the health status of farmers with intermediary variables has no intermediary effect. This means that the route through which the NRCMS health effect is exerted on farmers' formal credit availability is not statistically significant.

Householders' health status reflects future solvency to some extent, and theoretically has a significant positive effect on the level of credit availability. However, the regression results in Table 3 lead towards the opposite conclusion, as has already been noted. One possible explanation is that the continuous advance of industrialization and urbanization makes farmers' non-agricultural income generally higher than their farming income. The NRCMS can improve farmers' health and promote their nonagricultural work at the same time, which leads to lower investment in agricultural production and reduces demand for production credit. The relatively low labor efficiency of farmers with poor health means that non-farm employers 'rationally' generally employ none or only a few of them. It is therefore the case that farmers with poor health can often only 'stay' on the land to engage in agricultural production. But the implicit 'mortgage' function of the NRCMS increases the probability these farmers will obtain credit from financial institutions.

Table 3 Test of Role of Health Mediators

\section{(IV) Test of Economic Effect of NRCMS}


It therefore appears that the economic effect, in addition to the health effect, can influence formal credit availability. The observation (see Table 3) that the health effect is not significant raises the question of if this also extends to the economic effect. Table 4 presents the test results for the mediating effect of household economic pressure ${ }^{\circledR}$.

First, with regard to the impact of household participation rate on family medical pressure, column (1) of Table (4) shows that the coefficient of household participation is significant at a one percent level, which indicates that when the participation rate is higher, it is more likely the household will experience medical economic pressure. In the case of the marginal effect, every one percent increase in participation will generate a 4.9 percent increase in the probability that farmers will experience a medical economic burden. This may be because the NRCMS, as a kind of medical insurance, could create a moral hazard. It could lead to over-diagnosing, over-prescribing and even price increases, and impose a greater medical burden on farmers.

Second, with regard to the impact of medical burden on formal credit, columns (2) and (3) of Table 4's regression results confirm that the family medical burden significantly impacts credit availability and average credit acquisition, which indicates that the medical burden has significantly stimulated farmers' access to formal credit. When compared against the regression results of Table 2 (2) and (4), the coefficients of the NRCMS variables are smaller and become insignificant when the family medical burden variables are added as intermediary variables. The test standard of intermediary effect establishes that the variable of medical economic burden has completed intermediary effect.

It is normally the case that an increased medical burden will significantly deteriorate farmers' credit qualifications. But the study results show that when farmers face the medical burden, the availability of formal credit is significantly improved. One explanation is that the NRCMS, as a rural social security system that enjoys a direct capital injection from the Government, does not only improve the health status of

(9) The empirical medical pressure is based on the premise that the annual family medical expenses/family income exceeds 20 percent. It is possible that the empirical results based on 40 and 60 percent of the standard leads towards the same conclusion, but the results cannot be listed here due to limited space. 
householders but can also relieve the medical burden and assume financial functions.

The system's compensation policy ensures that farmers will receive a certain proportion of reimbursement compensation when they incur a medical burden. In recent years, the Government has also promoted health poverty alleviation and financial poverty alleviation projects and has sought to increase financial investment and improve reimbursement levels in order to resolve the costs and difficulties associated with medical treatment.

In other words, when participating farmers need to borrow for medical treatment, the Government can provide them with a 'government credit' mortgage that helps to relieve their credit constraints. Some regions have, in adjusting to this reality, sought to address demand for farmers' medical credit by introducing medical consumption loans that effectively graft credit loans and new rural cooperative funds, and this has helped to address the problems that farmers encounter when they seek to finance medical treatment. For example, Kaiyang County's Credit Union of Guizhou Province issued nearly 13 million yuan of 'KangFuTong' medical loans in 2015, and this enabled 699 poor families to access medical funds. ${ }^{\text {(1) }}$

Table 4 Mediating Effect of Medical Economic Pressure

\section{(V) Robustness test}

Models (1) and (2) are likely to suffer from endogenous problems. In the first instance, the endogenous source is the common adverse selection in the insurance market. This means the participating farmers have unobservable heterogeneity, which may affect access to credit and result in the stochastic interference terms of the econometric equation being correlated with independent variables (Cohen and Siegelman, 2009).

(10) Kaiyang County: Exploring and Promoting individual Medical Consumption Loan for Poor Farmers- Guizhou News-China Net-Donghai Information. http://jiangsu.china.com.cn/html/2016/gznews_0317/4822381.html 
But reverse causality, such as access to credit, may affect farmers' health level ${ }^{11}$, and could then affect NRCMS participation. In referring to the endogenous treatment of participation, this paper seeks to use the participation ratio of village members as a tool variable. There are two main reasons for adopting this method.

First, the implementation of the NRCMS is based on the principle of farmers' voluntary participation. Different farmers in the same village may therefore show the 'group effect' in participation when they make decisions (i.e. they will imitate and influence each other) but the village participation rate will not affect the sample individuals' credit behavior.

Second, the NRCMS adopts a partial burden system in the compensation mechanism, and this especially true of the compensation mechanism for hospitalization. The principle of 'more reimbursement of primary hospitals and less reimbursement of high-level hospitals' is established and different health governance levels (including village (town) hospitals, county (city) hospitals and hospitals outside the county) are determined to have different capping, paying and starting lines and compensation ratios. This shows that farmers' participation in decision-making behavior is not related to the situation of village-level medical facilities, and this guarantees that instrumental variables are exogenous.

Table 5 shows the regression results of the impact of the NRCMS on farmers' formal credit availability after the use of instrumental variables. The estimation results, when compared against the results without instrumental variables, the coefficients of 'whether the householder participates' and proportion of households do not show significant change, and this indicates that after the endogenous problem is considered, the NRCMS still has a significant positive impact on farmers' formal credit. The paper's results are therefore quite stable.

11 No empirical analysis has yet confirmed the impact of credit availability on farmer health levels. 


\section{Conclusions}

This paper first made the theoretical proposition that the impact of the NRCMS on farmers' credit availability is mainly embodied in a health and economic effect. It then proposed to apply data from the 2010 China Family Panels Survey (CFPS) for purposes of empirical analysis. The results show that the NRCMS has a significant positive impact on farmer's formal credit availability and credit amount, and it also highlights that this effect is mainly exerted on farmers' formal credit availability through the path of economic effect.

This study shows that the NRCMS is a social security system that the Government directly injects with capital. In addition to improving farmers' medical security, it also provides them with good 'collateral', which helps to increase their ability to repay credit and improves their credit access. This provides a new perspective for the Government that enables it to implement Inclusive Finance, use the 'collateral' function of public health insurance policy, innovate in financial services, effectively combine the new rural cooperative funds and financial institutions and resolve the formal credit constraints that farmers face. This helps to achieve the policy goal of reducing poverty and increasing farmers' income.

\section{Discussion}

The government in China is actively promoting inclusive finance, with the aim of making financial services more available to rural residents, and the low-income and poor in particular. But factors such as health or disease pressure, in addition to a lack of necessary collateral, mean that it is still difficult for farmers to access formal credit services. These conclusions will help to evaluate the policy effect of the NRCMS and improve farmers' access to formal credit, and this will in turn help to achieve rural financial inclusiveness. The promotion of inclusive finance, the increased availability of farmer financial services and the resolution of farmers' financing difficulties (such 
as medical credit constraints) have all become important parts in rural China.

This paper has been constrained by data limitations, and this has meant that it has only been able to explore the short-term impact of the NRCMS on farmer's formal credit availability. Ma et al.(2016) have pointed that periodic monitor and assessment could help adjust such policies timely to achieve the designed aims. Panel tracking data can theoretically be used to comprehensively examine the impact mechanism, and this requires us to continue to track and explore. In terms of use, credit can be divided into production managerial credit and life consumption credit; however, subdivision data is difficult to obtain, and this is why this paper uses the total credit data. Future research should therefore focus on the detailed study of credit use, combine the internal mechanism in accordance with credit use and conduct more targeted empirical tests.

Ethics approval and consent to participate: Not applicable.

Consent for publication: Not applicable.

\section{Availability of data and materials:}

The datasets during and/or analysed during the current study available from the corresponding author on reasonable request.

\section{Competing interests:}

The authors declare that they have no competing interests

\section{Funding:}

This study was supported by National Natural Science Foundation of China (No.71673173), China Postdoctoral Science Foundation (No.2019M661455), Program for Innovative Research Team of Shanghai University of Finance and Economics (No.2018110693), Graduate Innovation Foundation of Shanghai University of Finance and Economics (No. CXJJ-2019-433) and the Fundamental Research Funds for the Central Universities (No.2019110104, No. 2019110244, No. 2017110478) .

We would like to extend our sincere thanks to all above projects for supporting the study. 


\section{Authors' Contributions:}

Jin Liu and Qing Xu contributed to the conception and design of the study, offered supervision and revised the manuscript, and contributed to the funding acquisition. Yufeng Lu and Qing Yang contributed to the data analysis and the original draft. All authors read and approved the final manuscript.

\section{Acknowledgements:}

The authors would like to express their gratitude to the China Family Panel Studies (CFPS) research team and the field team for their collecting the data. The authors would like to express their gratitude to EditSprings (https://www.editsprings.com/) for the expert linguistic services provided.

\section{Authors' information:}

Qing $\mathrm{Xu}$ is a professor in Research Institute for Agriculture, Farmer and Rural Society in China, Institute of Finance and Economics, Shanghai University of Finance and Economics. His email is xu.qing@mail.shufe.edu.cn.

Jin Liu is the corresponding author. He is a lecture in Research Institute for Agriculture, Farmer and Rural Society in China, Institute of Finance and Economics, Shanghai University of Finance and Economics. His email is liu.jin@mail.shufe.edu.cn.

Qing Yang is a postdoctoral in School of Public Economics and Administration, Shanghai University of Finance and Economics.His email is yangqing@163.shufe.edu.cn.

Yufeng Lu is a Ph.D candidate in Research Institute for Agriculture, Farmer and Rural Society in China, Institute of Finance and Economics, Shanghai University of Finance and Economics. Her email is luyufeng421@163.com

\section{Reference:}

Bai, C., Wu, B., 2014. Health insurance and consumption: Evidence from China's New Cooperative Medical Scheme. Journal of Comparative Economics, 42(2), pp. 450-469.

Baron, R. M., Kenny, D. A. ,1986. The Moderator-Mediator Variable Distinction in Social Psychological Research: Conceptual, Strategic, and Statistical Considerations. Journal of Personality and Social Psychology, 51(6), pp.1173-1182. 
Cai, L., 2010. The Relationship between Health and Labour Force Participation: Evidence from a Panel Data Simultaneous Equation Model. Labour Economics, 17, pp. 77-90.

Cai, L., Mavromaras, K., Oguzoglu, U., 2014. The Effects of Health and Health Shocks on Hours Worked. Health Economics, 23(5), pp. 516-528.

Cheng, L., Liu, H., Shen, K., Zhang, Y., Zeng, Y., 2015. The Impact of Health Insurance on Health Outcomes and Spending of the Elderly: Evidence from China's New Cooperative Medical Scheme. Health Economics, 24(6), pp. 672-691.

Cohen, A., Siegelman, P., 2009. Testing for Adverse Selection in Insurance Markets. Social Science Electronic Publishing, 81(4), pp. 709-734.

Duong, P. B., Izumida, Y., 2002. Rural Development Finance in Vietnam: A Microeconometric Analysis of Household Surveys. World Development, 30(2), pp. 319-335.

Feder, G., Onchan, T., Raparla, T., 1988. Collateral, Guaranties and Rural Credit in Developing Countries, pp. Evidence from Asia. Agricultural Economics, 2(88), pp.231-245.

Feder, G., Lau, L., Lin J., Luo, X., 1990. The Relationship between Credit and Productivity in Chinese Agriculture: A Microeconomic Model of Disequilibrium. American Journal of Agricultural Economics, 72(5), pp. 11511157.

Fei, X.T. ,1985. Rural China. Beijing: SDX Joint Publishing Company, 1985.06, Edition 1. [In Chinese]

Grossman, M., 1972. On the concept of health capital and the demand for health. The Journal of Political Economy, 80 (2), pp. 223-255.

Hou, Z., Van de Poel, E., Van Doorslaer, E., Yu, B., Meng, Q., 2013. Effects of NCMS on Access to Care and Financial Protection in China. Health Economics, 23(8), pp. 917-934.

Lai, S., Shen, C., Xu, Y., Yang, X., Si, Y., Gao, J. et al., (2018). The distribution of benefits under China's new rural cooperative medical system: evidence from western rural China. International Journal for Equity in Health, 17(1). doi:10.1186/s12939-018-0852-7

Li, C., Lin, L., Gan, C. E. C., 2016). China credit constraints and rural households' consumption expenditure. Finance Research Letters, 19, pp. 158-164.

Ma, J., Xu, J., Zhang, Z., Wang, J., 2016. New cooperative medical scheme decreased financial burden but expanded the gap of income-related inequity: evidence from three provinces in rural China. International Journal for Equity in Health, 15, pp. 72.

Mitra, S., M. Palmer, D. Mont, et al., 2016. Can Households Cope with Health Shocks in Vietnam? Health Economics, 25(7), pp. 888-907.

Mushkin, S. J. .1962. Health as an Investment. Journal of Political Economy, 70(S5), pp. 129-157. 
Qin, X., Pan, J., Liu, G. G., 2014. Does participating in health insurance benefit the migrant workers in China? An empirical investigation. China Economic Review, 30, pp. 263-278.

Sen, A. 1999. Development as Freedom, Published by Alfred A Knopf.

Shen, Z., Parker, M., Brown, D., Fang, X., 2017. Effects of public health insurance on labor supply in rural China. Annals of Global Health, 83(1), pp. 127-128.

Smith, J.P., 2015. Economic shocks, early life circumstances and later life outcomes: Introduction. The Economic Journal, 125, pp. 306-310

Stiglitz, J. E., A. Weiss., 1981. Credit Rationing in Markets with Imperfect Information. American Economic Review, 71(71), pp. 393-410.

Strauss, J., 1986. Does Better Nutrition Raise Farm Productivity? The Journal of Political Economy, 94(2), 297-320.

Wagstaff, A., Lindelow, M., Jun, G., Ling, X., Juncheng, Q., 2009. Extending health insurance to the rural population: An impact evaluation of China's new cooperative medical scheme. Journal of Health Economics, 28(1), pp. 119.

Wooldridge, J. M. ,2003. Econometric Analysis of Cross Section and Panel Data. Published by The MIT Press.

Yuan, Y., Xu, L., 2015. Are poor able to access the informal credit market? Evidence from rural households in China. China Economic Review, 33, pp. 232-246.

Zhang, J.H., Liu, J., Xu, Q., 2016. New Rural Cooperative Medical System, Land Transfer and Land Retention. Management World, 1, pp. 99-109. [In Chinese]

Zhong, H., 2011. Effect of patient reimbursement method on health-care utilization: evidence from china. Health Economics, 20(11), pp. 1312-1329.

Zhou, Y., Guo, Y., Liu, Y., 2020. Health, income and poverty: evidence from China's rural household survey. International Journal for Equity in Health, 19(1). doi:10.1186/s12939-020-1121-0 


\section{Supplementary Files}

This is a list of supplementary files associated with this preprint. Click to download.

- TablesNRCMSandRuralHouseholdCreditAvailabilityinChina.doc

- TablesNRCMSandRuralHouseholdCreditAvailabilityinChina.doc 